DOI: $10.17805 /$ trudy.2015.3.4

\title{
ЗАКОНОДАТЕЛЬСТВО О КУЛЬТУРЕ В РОССИЙСКОЙ ФЕДЕРАЦИИ: БАЗОВЫЕ ПРИНЦИПЫ
}

\author{
A. В. Костина \\ (Московский гуманитарный университет)
}

Аннотация: В статье анализируется текст утвержденного в 2014 2. Указом Президента В. В. Путина Основ государственной культурной политики. Рассматриваются некоторые принципиальные позиции, подчеркиваются важные пункты, отмечаются недочеты документа.

Ключевые слова: Основы государственной культурной политики РФ, культурная политика, Россия, культура.

\section{LEGISLATION ON CULTURE IN RUSSIAN FEDERATION: BASIC PRINCIPLES}

\author{
A. V. Kostina \\ (Moscow University for the Humanities)
}

Abstract: The article analyzes the Foundations of State Cultural Policy approved by the decree of president Vladimir Putin in 2014. We look at the document's most important provisions, fundamental premises and some of its faults.

Keywords: Foundations of State Cultural Policy of the Russian Federation, cultural policy, Russia, culture.

С 23 апреля 2014 г., когда советником Президента по культуре В. Толстым был передан Президенту Проект «Основ государственной культурной политики РФ», в России шло обсуждение этого документа, содержание которого отражает не столько нынешнюю практику управления сферой культуры, сколько те цели, задачи и основные принципы, которые должны стать основой законодательного обеспечения политики в отношении культуры в будущем.

24 декабря 2014 г. Указом Президента РФ Основы государственной культурной политики были утверждены (Утверждены Основы ..., 2014: Электр. ресурс). Представляется целесообразным отметить целый ряд принципиальных позиций, отраженных в этих документах. Остановлюсь только на некоторых из них. 


\section{Культура как основа национальной идентичности}

Видится продуктивной позиция, связанная с пониманием культуры в России в качестве основы идентификации ее граждан и основания для формирования национально-культурной идентичности, что соответствует ведущей цели культурной политики, которой является «сильная, независимая во всех отношениях Россия».

Важность этого тезиса связана с тем, что, несмотря на сходство развития стран, имеющих более или менее близкие экономические и общественные системы, основы формирования национальных культур этих государств и - соответственно - процедуры выстраивания идентичности в них различны. Несмотря на то, что все нации основаны на гражданстве, на общности законов и правовых институтов, объединяющих ее членов общим кодексом, едиными правами и обязанностями; несмотря на то, что национальная идентичность складывается изначально как основанная на политических принципах, а источником суверенитета становится нация, сам характер идентификации в разных государствах существенно различается. В России достижения в социально-экономической области в меньшей степени являются предметом национальной гордости, чем достижения в сфере культуры - в науке, искусстве, литературе, а также в сфере истории ${ }^{1}$. То есть, культурная идентичность для россиян обладает гораздо большей значимостью, чем идентичность политическая. Точно так же, как история и достижения в сфере искусства и литературы обладают большими маркирующими чертами, чем достижения в научной сфере. Культурная идентичность, которая проявляется, прежде всего, в языковой общности, возможности общаться на одном языке, а также религиозная терпимость и взаимопонимание между различными религиозными конфессиями, сложившееся исторически, в России проявляются гораздо ярче, чем во многих других полиэтнических государствах.

\section{Язык как средоточие смыслов и ценностей культуры}

В документах определяются и те сферы, которые способствуют формированию этого гражданского единства. Вызывает удовлетворение тот факт, что особое внимание уделяется образованию и языку. В целях поддержания и укрепления гражданского и культурного единства фиксируется необходимость развития и защиты «русского языка - государственного языка Российской Федерации и языка национального общения» (Основы государственной ..., 2014: 4). Действительно, национальный литературный язык и национальная литература являются основой и воплощением того содержания, тех идей и ценностей, которые являются основополагающими в культуре.

Особое внимание к проблеме языка связано с множеством факторов. Прежде всего, язык является мощным интегрирующим фактором, позво- 
ляющим фиксировать значительные объемы информации и обеспечивать циркуляцию ценностей, смыслов и значений в рамках определенных сообществ. Общность языка становится основой национального сознания. Она, как точно отмечает Б. Андерсон, создает поля обмена и коммуникации, которые образуют первые «зародыши» национальных сообществ; она помогает создать образ истории, имеющий основополагающее значение для представления о нации (Anderson, 1983: 47). Именно поэтому можно говорить о том, что русская национальная культура началась с А. С. Пушкина, создавшего литературный язык, основанный на речевых оборотах, не только адекватно отражающих образ отечественной национальной культуры, но равно доступный по смысловому содержанию и образу отражаемой реальности представителям всех сословий.

Любой язык основывается на целом пласте познавательных, нормативных и эмоциональных коннотаций. Каждая культура обладает собственным вербальным арсеналом, где понимание происходит, в первую очередь, на уровне общего поля смыслов и значений, всего комплекса выразительных средств. Само же слово функционирует наиболее оптимальным способом исключительно в определенном языковом контексте, вскрывающем все оттенки его значений и выступает как исторически обусловленное, где за каждым из слов стоит весь образ жизни данного народа с его ценностными приоритетами, его менталитет, национальный характер, традиции, обычаи, мироощущение и видение мира. И разрушение национального языка неизбежно ведет к разрушению национальной культуры, что прекрасно осознают правительства стран, стремящихся ограничить влияние языков других государств ${ }^{2}$.

Представляется необходимым подчеркнуть еще раз: развитие русского языка - условие гражданского единства. Эти положения коррелируют с Концепцией государственной миграционной политики Российской Федерации на период до 2025 года, где отмечается необходимость развития в обществе межнациональных и межрелигиозных отношений, создания условий для адаптации и интеграции мигрантов, «включая их обучение русскому языку, правовое просвещение, информирование о культурных традициях и нормах поведения путем формирования соответствующей инфраструктуры в странах их происхождения и в регионах Российской Федерации, испытывающих наибольший приток мигрантов». Это необходимо для «противодействия социальной исключенности мигрантов, пространственной сегрегации и формированию этнических анклавов» (Президент утвердил Концепцию ..., 2012: Электр. ресурс), создающих значительную напряженность в обществе.

Поддержание русского языка ни в коей мере не означает дискриминации малых народов, культура и язык которых законодательно защищается. Преодоление этнической замкнутости этих народов привело к 
интенсивному развитию и их собственных культурных традиций, в частности, посредством развития письменности, литературы, науки и искусства. Однако в пространство мировой культуры эти народы вошли, преимущественно, через общенациональную культуру - как «русских» знал весь мир таких писателей, поэтов и композиторов, как киргиза Ч. Айтматова, аварца Р. Гамзатова, белоруса В. Быкова, армянина А. Хачатуряна, украинца Ю. Мейтуса, которые представляли не только свой народ, но и общенациональную культуру России.

Сегодня, во многом благодаря СМИ, в общественном сознании доминирует подход к народам и их культурам как к обладающим, по преимуществу, этнографической спецификой, при этом, к сожалению, понятие «российский народ», «россияне», воспринимается как искусственный конструкт. Между тем, «историческая Россия - не этническое государство и не американский «плавильный котел», где, в общем-то, все так или иначе - мигранты. Россия возникла и веками развивалась как многонациональное государство. Государство, в котором постоянно шел процесс взаимного привыкания, взаимного проникновения, смешивания народов на семейном, на дружеском, на служебном уровне. Сотен этносов, живущих на своей земле вместе и рядом с русскими. Освоение огромных территорий, наполнявшее всю историю России, было совместным делом многих народов. Достаточно сказать, что этнические украинцы живут на пространстве от Карпат до Камчатки. Как и этнические татары, евреи, белорусы» (Путин, 2012: Электр. ресурс). С этим тезисом Президента России трудно не согласиться.

Действительно, понятие «россияне», которое сегодня некоторым представляется неким политическим эвфемизмом, за которым якобы скрывается нежелание называть каждый народ своим собственным названием, представляется не только вполне легитимным, но и верно отражающим суть нации. Россияне - это все граждане России, вне зависимости от их этнического происхождения. Россияне - это нация, причем, сложившаяся естественным путем посредством длительного взаимодействия разных народов друг с другом и закрепленная конституционно. Таким образом, тезис о необходимости для всех граждан, получивших среднее образование, обязательное владение русским языком, а для иностранных граждан - обязательность обучения русскому языку «в объемах, необходимых для их трудовой деятельности в России и для защиты их прав» (Основы государственной ..., 2014: 4) представляется верным и соответствующим ведущим принципам современного общественного развития. 


\section{Культура: не сфера предоставления услуг, а основная цзель развития общества}

Еще одним принципиальным моментом является фиксация необходимости изменения «представлений органов власти и граждан о том, что культурная деятельность является сферой услуг», принципиально не отличающейся «от организации и оценки деятельности, например, бань, прачечных, собесов или почты» (там же: 5).

Это положение, несмотря на публицистичность стиля, представляется абсолютно точным. Распространение рыночной экономики привело к пониманию принципиально не рыночных сфер - прежде всего, культуры и образования, - как источника предоставления услуг. И в понимании культуры, к сожалению, стала доминировать практика тех государств, где культура рассматривается как индустрия культуры, которая, соответственно, входит в состав индустрии развлечений, что позволяет рассматривать ее как экономическую сферу. Если эта проблема только обозначалась в 1980-е годы, то к настоящему времени она приобрела столь выраженную остроту, что генеральный директор ВТО, созданной в 1995 г. как раз для регламентации прав международной торговли, был вынужден признать, что есть вопросы, которые в рамках Организации не могут быть решены. Среди них - вопрос о трактовке культуры.

В дискуссиях по проблеме определились два подхода. Согласно первому, культурный продукт является коммерческим продуктом индустрии развлечений и подлежит общему регулированию. К сожалению, в данных обстоятельствах единственным ценностным критерием как высокой и традиционной культуры, так и массовой, становится потребительская, обменная стоимость, «конвертируемость», благодаря чему все эти типы культуры сосуществуют в экономическом пространстве в качестве некоего обменного эквивалента. Согласно второму, культурный продукт рассматривается как актив, связанный с ценностями, идеями и смыслами, как инструмент культурной коммуникации, влияющий на формирование идентичности, и в этом своем качестве он не может рассматриваться в контексте требований по его изъятию или ограничениям.

По сути, здесь идет речь о двух совершенно различных сферах - с одной стороны, о высокой профессиональной и народной культуре, с другой стороны - о массовой культуре. Понятно, почему в американской политике эти сферы фактически не разделяются. Оторванность от корневой европейской традиционной культуры и разрушение традиционной культуры американских индейцев привели к пониманию культуры как коммерческого предприятия: культуры в целом - как одной из отраслей экономики, массовой культуры - как индустрии развлечений, этнической культуры - как предприятия по изготовлению и продаже туристам изделий, имитирующих аутентичные образцы, в основном, традиционного искусства индейцев. 
Однако Америка является образцом совершенно уникального создания мощного многонационального государства искусственным путем, где около ста этносов фактически не имеют общей истории, а их формирование происходило в совершенно различных культурных обстоятельствах. Во всех же иных полиэтнических государствах - в том числе, в России, в состав которой входит около 120 народов и этносов, сохранились живые традиции практически каждого из них. Поэтому и в европейской и в отечественной науке сфера культуры всегда соотносилась с ценностями, восприятием мира, особым образом жизни, ментальностью, способом отношения с миром. Но никогда - со сферой экономики!

Американская же культура, которая практически сразу рождалась как популярная, изначально была рождена как сфера экономического производства. Сегодня шоу-бизнес выступает в качестве такой же производственной сферы, как и экономика, а борьба за право управлять «культурными интересами» человечества становится такой же напряженной и острой, как и борьба за территории и рынки сбыта в рамках индустриальной культуры. Как достаточно цинично отметил представитель Виакома, корпорации, подчас выступающие в качестве деловых партнеров, разворачивают борьбу тогда, когда речь идет о «получении доступа к 5060-ти миллионам зрителей и слушателей» (Frank, 1998: 48). В это время, как сказал в свое время президент корпорации SONY в США Г. Стингер, «каждый дом становится полем битвы» (цит. по: там же: 46).

Влияние этой тенденции рассматривать и оценивать все явления - в том числе, и явления высокой культуры, с точки зрения не их духовного значения, а их экономической стоимости, сегодня достаточно ощутимо. Доминирование этой позиции в современном обществе приводит к распространению «экономикоцентричной» рыночной психологии и обусловливает практику неверного истолкования культуры как сферы развлечений, досуга или в качестве экономической сферы. И, несмотря на то, что сегодня повсеместно отстаивается точка зрения о том, что культура - это специфический механизм, при помощи которого формируется общее пространство смыслов и ценностей, позволяющее обществу существовать в качестве устойчивой системы и обеспечивающее возможность мобилизации ее потенциала в сложных исторических ситуациях, восприятие культуры как сферы, которая может и должна приносить прибыль, является достаточно распространенным.

И в этом смысле тезис о неверности понимания культуры как сферы услуг представляется чрезвычайно своевременным. 


\section{Массовая культура как механизм формирования социальной солидарности}

Наконец, еще один тезис, требующий комментариев. Это тезис о необходимости выработки форм государственного регулирования сферы массовой культуры «как преобладающего фактора культурного воздействия на граждан и взаимодействия профессиональной и массовой культуры» (Основы государственной ..., 2014: 5).

Действительно, массовая культура является специфическим механизмом, обладающим весьма значительным конструктивным социальным потенциалом в современном обществе. Это связано с тем, что массовая культура и возникла на рубеже XIX-XX вв. в тех условиях, когда массовое общество только начало приобретать свои классические очертания и когда возникла необходимость элиминировать его нестабильность, конфликтность, противоречивость. Массовая культура должна была защитить общество от распадения под влиянием социальных катаклизмов, сформировать те каналы коммуникации, по которым будет циркулировать социально значимая информация, наладить в культурном сообществе взаимообмен смыслами, выработать общность картины мира, единые стандарты поведения, цели и ценности.

Для реализации этой функциональности массовая культура выработала целый арсенал средств и механизмов, которые были направлены на реализацию стратегий управления обществом. Эту функцию массовой культуры примерно с середины прошлого столетия ее критики небезосновательно называли «манипулятивной», имея в виду способность этой культуры к активному воздействию на массовое сознание. Затем - спустя несколько десятков лет - начали говорить о ее способности «мягко управлять, соблазняя», тот есть, осуществлять не жесткий тотальный контроль масс, а незаметное и не вызывающее сопротивления управление.

Несмотря на то, что наше сознание, воспитанное в духе ценностей либерализма, сопротивляется приятию этого факта как некоей социальной нормы, а также, несмотря на то, что мы определяем свое поведение и линию поступков как продиктованные исключительно собственной волей и рассудком, влияние массовой культуры мы все равно испытываем. Это связано с тотальностью ее проявлений, разнообразием ее форм и стремительностью расширения ареала ее существования. Однако этот факт не является столь негативным, напротив, массовая культура - это, конечно, и определенное содержание - упрощенное, поверхностное, развлекательное, но и форма представления этого содержания, механизм его распространения, те каналы коммуникации, которые позволяют функционировать информации, имеющей существенное социальное и культурное значение. 
Кроме того, массовая культура эффективно участвует в процессах создания гражданской идентичности. Вопреки сложившемуся мнению о том, что общенациональная культура создается только через механизмы высокой специализированной культуры - через образование и институты музеев, театров, библиотек, можно с уверенностью утверждать большое значение в этих процессах и массовой культуры. Она формирует национальное единство через внятную идеологию, через сакрализацию истории народа, через систему социально значимых мифов и проективных значений.

Важным для понимания сущности массовой культуры является ее признание в качестве специфической универсальной формы, обладающей особой размерностью и коммуникабельностью. Ее же содержание определяется ее субъектом, в качестве которого выступает не столько особая профессиональная группа, создающая ее артефакты в соответствии с законами социальной психологии и рыночных отношений, сколько представители финансовой и политической элиты - владельцы каналов коммуникации.

Но ведущим субъектом массовой культуры должно являться государство, и это - принципиальный момент. От того, какое содержание будет заложено в массовую культуру, такую функцию она и будет выполнять - через формирование национального достоинства она может укрепить целостность государства, через насаждение чуждой идеологии может его разрушить, выступая своеобразным аналогом «пятой колонны».

Фактически это и происходило после распадения Советского Союза, когда поток западной массовой культуры - рекламы, фильмов, передач и т. п., - хлынувший из стран «победившего капитализма», завершал дело разрушения государства через разрушение его ценностей, смыслов и идей. Создавая особую реальность и особую технологию производства этой реальности, массовая культура как «великий агент глобализации» (3. Бжезинский, Р. Стил) стала производить и соответствующее ей глобальное сознание, опирающееся на ценности западной цивилизации и ее мировоззренческие установки, основу которых составляет философия позитивизма и прагматизма с ее принципами инструментализма и операционализма.

Но сегодня ситуация меняется. Массовая культура обращается к отечественной истории и ее славным именам. Можно приветствовать сегодня рождение таких фильмов, как «Высоцкий. Спасибо что живой», «Гагарин. Первый в космосе», «Легенда № 17», которые возвращают в сознание россиян забытые имена и великие события, позволяя еще раз осознать значимость собственной истории.

Представляется принципиально важным, что значение массовой культуры для общества и необходимость использования ее механизмов в целях формирования национального единства рассматривается на уров- 
не первых лиц государства. Так, в статье Президента России «Россия: национальный вопрос» отмечается: «Соответствующие требования должна задавать и государственная политика в области культуры. Имеются в виду такие инструменты, как телевидение, кино, Интернет, массовая культура в целом, которые формируют общественное сознание, задают поведенческие образцы и нормы. Вспомним, как американцы с помощью Голливуда формировали сознание нескольких поколений. Причем внедряя не худшие - и с точки зрения национальных интересов, и с точки зрения общественной морали - ценности [...]. Государство обязано и имеет право и свои усилия, и свои ресурсы направлять на решение осознанных социальных, общественных задач. В том числе и на формирование мировоззрения, скрепляющего нацию» (Путин, 2012: Электр. ресурс).

Таким образом, позитивный социальный потенциал массовой культуры огромен, его необходимо использовать в полной мере. Отрадно, что в последние годы в России обращается большое внимание на поддержание престижа отечественной культуры, на внимание к ее истории и к ее героям, реабилитируется то, что было предано забвению. Появляющиеся фильмы, посвященные нашим историческим свершениям, нашим спортивным достижениям (что стоит один фильм о Харламове!), Великой Отечественной войне, вызывающие все больший интерес. Не случайно на всех празднествах Олимпиады в Сочи все время воспроизводились реплики из Московской Олимпиады 1980 г. Таким образом, массовая культура должна развиваться как форма, способствующая развитию государства, закреплению его успехов, формированию единой нации, обладающей высокими целями своего развития.

Все эти положения представляются весьма позитивными.

Отрадно, что многие положения Проекта в основном законе были скорректированы. В частности, можно показать, что вызывало вопросы в Проекте Основ государственной культурной политики или представлялось дискуссионным, не в полной мере разработанным.

Во-первых, в Проекте ощущалась избыточность подчеркивания трансляционной и охранительной функции культуры, которая представлялась, как «инструмент передачи новым поколениям свода нравственных, моральных, этических ценностей», как обеспечение единства народа на основе «сохранения культурной и национальной самобытности», как знание, закладывающее в человеке «уважение к истории и традиции, духовным основам наших народов», как главный инструмент «передачи и воспроизводства традиционных нравственных ценностей», где ведущим становится понимание того, что «иного источника и основы для дальнейшего развития (речь о наследии. - примеч. автора) у России быть не может» (разделы I-III Проекта). 
С этими положениями невозможно не согласиться. Но хотелось бы, чтобы культура представала не как архив, музей, коллекция, собрание смыслов, а как такой феномен, без которого невозможно формирование и информационного общества, концепция формирования которого разработана и одобрена Решением Государственной комиссии по информатизации при Государственном комитете Российской Федерации по связи и информатизации еще 28 мая 1999 г. за № 32 (там же), и шестого технологического уклада, лидером которого, по мнению экспертов, может стать Россия - вместе с США, Японией, странами ЕС, Китаем (Глазьев, 2010: 88-90). Мемориальность культуры должна, как представляется, сочетаться с ее проективностью - ведь, как известно, только взаимодействие традиции и инновации обусловливает возможность гармоничного развития общества. Хотелось бы в основном документе увидеть понимание культуры, связанное с ее проективным потенциалом. Это первое.

Во-вторых, авторы Проекта абсолютно верно говорили о том, что в сфере искусства и культуры необходима поддержка научных исследований, называя эстетику, историю и теорию искусств, социологию и психологию культуры, литературоведение, языкознание, научное исследование нематериального культурного наследия и отмечая, что «без науки о культуре невозможна выработка объективных критериев оценки явлений культуры, прогнозирование перспектив ее развития» (Глава III, раздел 10). Все верно. Только почему не названа сама «наука о культуре» культурология?

Специфика того понимания культурологии, которое сложилось сегодня, состоит в рассмотрении ее как науки, стремящейся к синтезу различных подходов и выработке на их основе универсальной междисциплинарной теории, как науки, изучающей культуру в ее целостности в качестве сложного системного объекта, распадающегося на множество подсистем, отличающихся, в свою очередь, высокой степенью сложности. Синтетичность и междисциплинарность культурологии определяется ее нацеленностью не на суммирование тех знаний, которые накоплены в границах разных наук о культуре, а на их обобщение с целью создания целостного образа эпохи или культуры в процессе построения моделей различных культурных типов. Ни одна из названных наук этих задач не решает.

А между тем, эти проблемы были названы в самом Проекте Основ государственной культурной политики. Это: соотношение этнической и национальной культур; традиционной, высокой профессиональной и массовой культур; функции культуры (создание гражданской и культурной идентичности, формирование социальной целостности и солидарности); роль культурного наследия в развитии России; преемственность, передача ценностей и смыслов культуры, сохранение духовного опыта народа; 
развитие культуры в глобальном мире и мире высоких, в том числе, сетевых технологий; формирование креативного сознания, настроенного на производство новых смыслов культуры и т. д. и т. п.

Какая из названных наук направлена на осмысление этих проблем? Ни одна из них! К примеру, массовая культура может быть объектом рассмотрения социальной философии, традиционная культура - этнологии и фольклористики, высокая специализированная культура - искусствознания, литературоведения, истории и т. п. А культурология может не только рассматривать их в едином методологическом поле, но и выстраивать модели их взаимодействия, показывая их взаимную обусловленность, их высокую степень социальной функциональности - о чем говорится и в Проекте. Большим заблуждением является восприятие культурологии как науки, изучающей культуру только в процессе описания ее эмпирически наблюдаемых черт - ни один из научных текстов не может претендовать на принадлежность к культурологическому, если в нем представлен только эмпирический материал и отсутствуют серьезные обобщения, ради которых этот материал и приводится.

Культурология исходит из того понимания культуры, которое является основополагающим и в Проекте, - как сложившейся в историческом процессе устойчивой системы коллективного взаимодействия людей, а также совокупности продуктов, идей, структур и технологий, порожденных в процессе этого взаимодействия и следующих из практик осуществления жизнедеятельности в соответствии с этим порядком. Назначение культурологии - анализ культуры как в актуальном, так ретроспективном и перспективном планах, построение обоснованные прогнозов ее развития, выявление ее возможностей по формированию позитивных социальных практик и элиминирования негативных, создание теоретической базы для выработки соответствующей запросам социального и культурного развития информационной и культурной политики.

Представляется, что отсутствие упоминания о культурологии в Проекте Основ государственной культурной политики - хочется надеяться, случайное. В первую очередь это ослабляет не науку о культуре, а саму культуру. Представляется необходимым не только включить культурологию в перечень дисциплин, изучающих культуру, но и подчеркнуть ее доминирующее значение в этом ряду.

В заключении отметим следующее. Проект Основ государственной культурной политики представляется глубоким, продуманным, важным документом, верно выделяющим все основные проблемы, «болевые точки» и «точки роста» культуры. Он отличается концептуальностью, которая фиксируется в самом документе, отмечающем необходимость для реализации поставленных в Основах государственной культурной политики цели и задач реформирования существующей системы государ- 
ственного управления в сфере культуры - корректировки функций ряда министерств и ведомств, их полномочий и зон ответственности. Все это - наряду с фиксацией необходимости уточнения понятийного аппарата, а также проведения реформы юридической, организационной, методической - свидетельствует о широте замысла и серьезности намерений авторов Проекта, демонстрирующих понимание культуры как сферы, столь же значительной, как экономика, политика, наука.

Представляется важным следующее: многое из того, что представлялось дискуссионным в Проекте, было скорректировано в «Основах государственной культурной политики». И это показывает серьезное отношение к культуре со стороны государства и - соответственно - повышении статуса культурологии как науки о культуре и направлении подготовки специалистов в данной области.

\section{СПИСОК ЛИТЕРАТУРЫ}

Глазьев, С. Ю. (2010) Стратегия опережающего развития России в условиях глобального кризиса. М. : Экономика.

Мельник, Ю. В. (2003) Языковая глобализация // Глобалистика. Энциклопедия. М. : РОУ. 1416 с. С. 1304.

Основы государственной культурной политики. Проект (2014) // Культура. № 16. 16-22 мая. С. 4-5.

Президент утвердил Концепцию государственной миграционной политики Российской Федерации на период до 2025 года (2012) [Электронный ресурс] // Президент России. Официальный сайт. 13 июня. URL: http:// www.kremlin.ru/acts/15635 (дата обращения: 13.03.2015).

Путин, В. В. (2012) Россия: национальный вопрос [Электронный ресурс] //Независимая газета. 23 января. URL: http://www.ng.ru/politics/201201-23/1_national.html (дата обращения: 13.03.2015).

Утверждены Основы государственной культурной политики (2014) [Электронный ресурс] // Президент России. Официальный сайт. 24 декабря. URL: http://www.kremlin.ru/events/president/news/47325 (дата обращения: 13.03.2015).

Федорова, Т. С. (2005) Всемирный доклад по культуре - 2000 (обзор доклада ЮНЕСКО по культуре) // Эволюция культурной деятельности в новом столетии: Социально-экономические аспекты культурной политики : в 3 т. СПб. : Алетейя. Т. 2. Культура в глобальном мире. 524 с.

Anderson, В. (1983) Imagined Communities. Reflections on the Origin and Spread of Nationalism. London : Verso.

Frank, R. (1998) There is no business like show business // Fortune. № 12. P. 42-54. 
Примечания:

${ }^{1}$ См. данные Международной программы социологических исследований, осуществленной в 1995 г. (Федорова, 2005).

2 Так во Франции еще в 1994 г. был принят закон, ограничивающий употребление американизмов во французском языке, в Польше предприниматели платят дополнительный налог в случае использования иностранных слов в названии фирмы (Мельник, 2003: 1304).

Костина Анна Владимировна - доктор философских наук, доктор культурологии, декан факультета философии, культуры и искусства, заведующая кафедрой философии, культурологии и политологии Московского гуманитарного университета. Адрес: 111395, Россия, г. Москва, ул. Юности, д. 5. Тел.:+7 (499) 374-61-81. Эл. адрес: anna_kostina@inbox.ru

Kostina Anna Vladimirovna, Doctor of Science (philosophy and culturology), professor, the dean of the Philosophy, Culture and Arts Faculty, the head of the Philosophy, Culturology and Politology Department, Moscow University for the Humanities. Postal address: 5 Yunosti St., Moscow, Russian Federation, 111395. Tel.:+7 (499) 374-61-81.E-mail: anna_kostina@inbox.ru 